Foreword

\title{
PSOG No.5: Precision Surgery in Obstetrics and Gynecology: Radical Hysterectomy
}

Yuji Hiramatsu, MD, PhD ${ }^{1}$

${ }^{1}$ Department of Obstetrics and Gynecology, Okayama City General
Medical Center, Kita-Ku, Okayama, Japan

Surg J (NY) 2021;7(suppl S2):S47.

It is a great pleasure to publish the fifth issue of Precision Surgery in Obstetrics and Gynecology (PSOG), a supplement to The Surgery Journal. The fifth issue of PSOG focuses on "Radical Hysterectomy."

We previously published a Japanese book series (24 volumes), entitled Obstetric and Gynecologic Surgery Now (OGS Now) with the Japanese medical publisher, Medical View, Inc. In PSOG, we are selecting representative operations from OGS Now series and demonstrating the updated operative techniques.

Radical hysterectomy (RH) is the most difficult operation in gynecological surgery, and pelvic floor dissection and cavity expansion in this surgery are necessary knowledge and skills in general obstetrical and gynecological operations. In Japan, $\mathrm{RH}$ has been studied, improved, and advanced by many doctors since the publication of the Okabayashi's method. In this series, we covered Okabayashi's method, nerve-preserving RH, vaginal $\mathrm{RH}$, laparoscopic and robotic $\mathrm{RH}$, super-radical hysterectomy, and abdominal radical trachelectomy. All of them are written by the experts of the facility that draws the flow of the original technique, so they are full of useful information. We hope that the procedures listed in PSOG will be helpful to Ob-Gyn doctors around the world.

Finally, I would like to express my sincere thanks to Medical View for allowing us to use the illustrations and photos used in the OGS Now series.
Address for correspondence Yuji Hiramatsu, MD, PhD, Okayama City General Medical Center, 3-20-1 KitanagaseOmotematchi, Kita-Ku, Okayama 700-8557, Japan (e-mail: hiramatsu.enyu@gmail.com).
DOI https://doi.org/ $10.1055 / \mathrm{s}-0041-1739123$. ISSN 2378-5128.

\footnotetext{
(C) 2021. The Author(s).

This is an open access article published by Thieme under the terms of the Creative Commons Attribution-NonDerivative-NonCommercial-License, permitting copying and reproduction so long as the original work is given appropriate credit. Contents may not be used for commercial purposes, or adapted, remixed, transformed or built upon. (https://creativecommons.org/ licenses/by-nc-nd/4.0/) Thieme Medical Publishers, Inc., 333 Seventh Avenue, 18th Floor, New York, NY 10001, USA
} 